\title{
Cardiovascular System Findings Reference Identifier
}

National Cancer Institute

\section{Source}

National Cancer Institute. Cardiovascular System Findings Reference Identifier. NCI

Thesaurus. Code C162127.

A character or string used to name, or characterize a cardiovascular system findings reference. 